\title{
Prognostic implications of lymphocyte/C-reactive protein ratio with tumor-infiltrating lymphocytes in resected intrahepatic cholangiocarcinoma
}

Katsuki Miyazaki

Tokushima University https://orcid.org/0000-0003-0065-5296

Yuji Morine

Tokushima Daigaku

Satoru Imura

Tokushima Daigaku

Tetsuya Ikemoto

Tokushima Daigaku

Yu Saito

Tokushima Daigaku

Shinichiro Yamada

Tokushima Daigaku

Kazunori Tokuda

Tokushima Daigaku

Shohei Okikawa

Tokushima Daigaku

Shoko Yamashita

Tokushima Daigaku

Takeshi Oya

Tokushima Daigaku

Koichi Tsuneyama

Tokushima Daigaku

Mitsuo Shimada ( $\triangle$ mitsuo.shimada@tokushima-u.ac.jp )

Tokushima Daigaku

\section{Research}

Keywords: Lymphocyte/C-reactive protein ratio, tumor-infiltrating lymphocyte, intrahepatic cholangiocarcinoma

Posted Date: November 10th, 2020 
DOl: https://doi.org/10.21203/rs.3.rs-103094/v1

License: (c) (1) This work is licensed under a Creative Commons Attribution 4.0 International License. Read Full License 


\section{Abstract}

Background Lymphocyte/C-reactive protein (CRP) ratio (LCR), is a promising prognostic factor that can reflect tumor inflammation and systemic patient condition. The aim of this study was to investigate whether preoperative LCR can be a prognostic factor for post-surgical outcomes among patients with intrahepatic cholangiocarcinoma (IHCC). We also investigated the relationship between LCR and tumor infiltrating lymphocytes (TILs) to clarify whether systemic host immune parameters reflect local tumor immunity.

Methods We enrolled 45 patients who had undergone hepatectomy for IHCC. Patients were divided into low LCR and high LCR groups, according to reactive operating characteristic curve (Cut-off value: 8780). We analyzed their overall survival (OS) and disease-free survival (DFS) with respect to LCR and other clinicopathological factors. We also investigated stromal TILs and numbers of CD $8^{+}$TILs in surgical specimens, and the relationship between LCR and TILs.

Results Twenty-one patients (46.7\%) were associated with low LCR. Low LCR was significantly correlated with older age, high CRP and advanced disease stage, and was a prognostic factor for OS and DFS. And multivariate analysis revealed that low LCR was an independent prognostic factor for worse OS (HR: 2.81 $P<0.04)$. Regarding the relationship between LCR and local tumor immunity, while LCR and levels for stromal TILs were significantly related, LCR and levels for $C D 8^{+}$TILs were significantly related.

Conclusions Preoperative LCR levels could predict the post-surgical prognosis of patients with IHCC, and reflected numbers of intra-tumoral CD8 ${ }^{+}$TILs.

Trial registration This study was approved by Tokushima University Hospital ethics committee and with the approval of corresponding regulatory agencies, and all the experiments were carried out in accordance with the approved guidelines (Tokushima Clinical Trial Management System Number; 3215). All the patients involved in this study signed informed consent forms and agreed to participate.

\section{Background}

Although intrahepatic cholangiocarcinoma (IHCC) is the second-most common primary liver cancer after hepatocellular carcinoma (HCC), it is relatively rare, accounting for only $5 \%$ of primary liver cancers [1]. It is a biliary tract cancer derived from the intrahepatic bile duct epithelium. Complete resection is the most effective treatment for IHCC, when possible. However, IHCC has a high recurrence rate after resection, and therefore has a poor prognosis [2].

Various combinations of blood test indicators have been studied in recent years as prognostic indicators for cancer patients, including the neutrophil/lymphocyte ratio (NLR) [3, 4], Modified Glasgow Prognostic Score (mGPS) [5, 6], and the Prognostic Nutrition Index (PNI) [7, 8], among others. These combinations can represent systemic inflammation, immune function, and/or nutritional status. 
Reportedly, the preoperative platelet/lymphocyte ratio (PLR), systemic immune inflammation index (SII; platelets $\times$ NLR), and lymphocyte/monocyte ratio (LMR) are significantly associated with outcomes in patients with IHCC who undergo curative resection [9-11]. We have already focused on the prognostic effects of some proteins in resected IHCC specimens or preoperative image findings of IHCC patients. High expression of Heat Shock Protein 1 (HSF-1), and loss of Secreted Frizzled-Related Protein-1 (SFRP1) and F-box and WD repeat domain-contain 7 (FBXW7) in surgical specimens were associated with poor prognosis in IHCC patients [12-14]; as were low apparent diffusion coefficient of diffusion-weighted image magnetic resonance imaging, and central hypo-enhancement in hepatic arterial phase of dynamic computed tomography in preoperative images $[15,16]$.

After Okugawa et al. reported lymphocyte/C-reactive protein (CRP) ratio (LCR), a new immune-nutritional index, to be a strong prognostic factor for patients with colorectal cancer [17], LCR was also found to indicate prognosis of gastric cancer, pancreatic cancer, rectal cancer treated with chemoradiotherapy, and breast cancer. [18-21].

Whereas LCR and other immune-nutritional parameters represent the patient's systemic condition, tumorinfiltrating lymphocytes (TILs) may reflect local tumor immunity. Lymphocyte-predominant breast cancer (LPBC), which has high TIL levels, has a good prognosis [22]. Lee et al. reported a significant correlation between peripheral lymphocyte count and TILs in patients with cervical carcinoma [23], whereas Yoon et al. reported a significant relationship between TILs and peripheral neutrophil count in breast cancer [24]. $\mathrm{CD}^{+}$lymphocytes are considered to be especially crucial among TILs. Zhu et al. reported a correlation between tumoral programmed death ligand 1 (PD-L1) expression and CD8 ${ }^{+}$T-cell infiltration in IHCC patients [25], and Asahi et al. reported that numbers of $C D 8^{+}$T-cells in a tumor's outer border area were associated with postsurgical outcomes in patients with IHCC [26].

This study investigated the relationships between preoperative LCR and postsurgical outcomes in patients with IHCC, and between LCR levels and intra-tumoral TILs, to clarify whether systemic immune indicators reflect local tumor immunity.

\section{Methods}

\section{Patients}

We enrolled 45 patients who underwent primary hepatectomy for IHCC at Tokushima University Hospital between July 2002 and May 2015 in this study. We excluded patients who had undergone chemotherapy or radiation prior to surgery, or whose blood tests including cell fractions, were not measured within 4 weeks before surgery. We obtained data on other clinicopathological parameters from the medical database. The patients' median follow-up period was 2.5 years (range: $0.17-17.08$ ). This study was approved by Tokushima University Hospital ethics committee and with the approval of corresponding regulatory agencies, and all the experiments were carried out in accordance with the approved guidelines 
(Tokushima Clinical Trial Management System Number; 3215). All the patients involved in this study signed informed consent forms and agreed to participate.

\section{Treatment strategy for IHCC}

Patients were treated according to a previously described strategy for resectable IHCC $[15,27]$. Briefly, limited hepatectomy was performed without typical lymph node dissection or extrahepatic bile duct resection for peripheral tumors. For tumors in the perihilar region, or in the peripheral region with hilar infiltration, anatomical hepatectomy and regional lymph node dissection were performed. Extrahepatic bile duct resection and reconstruction were performed if needed for surgical margins.

\section{Preoperative immune parameters}

Blood samples were taken prior to hepatectomy. LCR was calculated by dividing total lymphocyte count $(\mathrm{TLC})(/ \mu \mathrm{L})$ by serum CRP $(\mathrm{mg} / \mathrm{dL})$. The optimal cutoff value for $\mathrm{LCR}$ was determined by using receiver operating characteristics (ROC) curves on mortality two years after surgery to assess early postoperative death. The cutoff value of LCR determined by ROC curve was 8780 (1-Specificity, Sensitivity: 0.296, 0.772; area under curve: 0.765$)$.

\section{Assessment of TILs}

TILs were evaluated according to the standardized methodology proposed by the International TIL Working Group [28]. In summary, rather than counting the number of lymphocytes, we assessed stromal TILs by calculating the ratio of TILs to stromal areas, excluding tumor cells, in hematoxylin and eosin (HE)-stained samples (Fig. 1a). We excluded the tumor cell areas (Fig. 1b) and calculated stromal and TILs areas (Fig. 1C) by using the image analysis software ImageJ (National Institute of Health). Assessments were performed in areas within the borders of the invasive tumor, and tumor zones with crush artifacts, necrosis, regressive hyalinization were excluded. We scored all mononuclear cells, including lymphocytes and plasma cells, but polymorphonuclear leukocytes or fibroblasts were excluded. After a full assessment of average TILs in the tumor border area, we assessed the stromal TILs averaged among three selected high-power fields ( $400 \times$ magnification), not focused on hotspots. Thus, we evaluated TILs for 38 patients whose HE slides were available, under the guidance of two expert pathologists who were blinded to clinical features.

\section{Assessment of CD8 ${ }^{+}$TILs}

Anti-CD8 antibody (dilution 1:100, M7103; Dako) was used as the primary antibody. We used immunohistochemistry procedures in our department that were previously reported by Ishikawa et al [29]. Selecting average regions within the tumor borders, we manually counted CD8 ${ }^{+}$TILs in three high-power fields (400 $\times$ magnification) per patient and calculated the mean number of CD8 ${ }^{+}$TILs, for the 31 patients whose samples were available. Figure 2 showed representative cases of high (Fig. 2a) and low (Fig. 2b) $\mathrm{CD} 8^{+}$TILs. These procedures were conducted under the guidance of two expert pathologists.

\section{Statistical analysis}


Cutoff values for immune-nutritional parameters and TILs were determined with ROC curves. We used the unpaired Mann-Whitney U-test or the $\chi 2$ test to compare clinicopathological variables between two groups. Overall survival (OS) and disease-free survival (DFS) curves were created using Kaplan-Meier method; differences were analyzed by log-rank test. The Cox proportional hazard regression model was used for multivariate analysis. $\mathrm{P}<0.05$ was considered significant.

\section{Results}

\section{Preoperative LCR levels can accurately reflect post-surgical prognosis}

Patients were divided into the high LCR $\left(\mathrm{LCR}^{\mathrm{High}}\right)$ group and the low LCR $\left(\mathrm{LCR}^{\mathrm{Low}}\right)$ group. Median values indicated that the $\mathrm{LCR}^{\mathrm{Low}}$ group was significantly older, and had higher CRP levels, longer surgeries, and more advanced disease than the LCR ${ }^{\text {High }}$ group (Table 1). Other host, surgical, and tumor factors did not significantly differ between the two groups. 
Table 1

Clinicopathological factors in the LCR high and low group

\begin{tabular}{|c|c|c|c|}
\hline Variables & $\begin{array}{l}\text { LCR }>8780 \\
(n=24)\end{array}$ & $\begin{array}{l}\text { LCR } \leq 8780 \\
(n=21)\end{array}$ & $P$-value \\
\hline \multicolumn{4}{|l|}{ Host factors } \\
\hline Age (y) & $67.1 \pm 7.5$ & $73.9 \pm 7.1$ & $<0,01$ \\
\hline Gender (M/F) & $17 / 7$ & $15 / 6$ & 0.96 \\
\hline $\operatorname{TLC}(/ \mu \mathrm{L})$ & $1586 \pm 578$ & $1414 \pm 455$ & 0.42 \\
\hline ANC $(/ \mu \mathrm{L})$ & $3480 \pm 1005$ & $4157 \pm 1525$ & 0.26 \\
\hline CRP (mg/dL) & $0.10 \pm 0.06$ & $0.93 \pm 1.60$ & $<0.01$ \\
\hline $\operatorname{NLR}(<2.24$ / $\geq 2.24)$ & $14 / 10$ & $7 / 14$ & 0.09 \\
\hline Frail $(-/+)$ & $18 / 6$ & $11 / 10$ & 0.11 \\
\hline $\operatorname{HBV}(-/+)$ & $18 / 6$ & $18 / 3$ & 0.37 \\
\hline $\operatorname{HCV}(-/+)$ & $21 / 3$ & $20 / 1$ & 0.35 \\
\hline \multicolumn{4}{|l|}{ Surgical factors } \\
\hline Operation time (min) & $346 \pm 110$ & $387 \pm 75$ & 0.02 \\
\hline Blood loss (mL) & $259 \pm 186$ & $372 \pm 289$ & 0.22 \\
\hline Postoperative complication $\left(-/+^{\star}\right)$ & $21 / 3$ & $19 / 2$ & 0.75 \\
\hline Operation ( $\mathrm{Hr} \mathrm{0,1} / \mathrm{Hr} 2,3)$ & $8 / 16$ & $6 / 15$ & 0.73 \\
\hline Curability (A, B / C) & $22 / 2$ & $12 / 9$ & $<0.01$ \\
\hline \multicolumn{4}{|l|}{ Tumor factors } \\
\hline Size $(<3 \mathrm{~cm} / \geq 3 \mathrm{~cm})$ & $7 / 17$ & $6 / 15$ & 0.68 \\
\hline Number (1 / 2 / 3) & $24 / 0$ & $16 / 3 / 2$ & 0.02 \\
\hline $\operatorname{LNM}(-/+)$ & $18 / 6$ & $14 / 7$ & 0.54 \\
\hline $\mathrm{vp}(-/+)$ & $16 / 8$ & $13 / 8$ & 0.74 \\
\hline $\operatorname{vv}(-/+)$ & $22 / 2$ & $18 / 3$ & 0.53 \\
\hline
\end{tabular}

ANC, absolute neutrophil count; CA19-9, carbohydrate antigen 19 - 9; CEA, carcinoembryonic antigen; CRP, C-reactive protein; HBV, hepatitis B virus; $\mathrm{HCV}$, hepatitis $\mathrm{C}$ virus; im, intrahepatic metastasis; LCR, lymphocyte-CRP ratio; LMN, lymph node metastasis; NLR, neutrophil-lymphocyte ratio; TLC, total lymphocyte count; vp, portal vein invasion; vv, hepatic vein invasion.

*Complications of Clavien-Dindo $\geq$ Illa were considered positive. 


\begin{tabular}{|c|c|c|c|}
\hline Variables & $\begin{array}{l}\text { LCR }>8780 \\
(n=24)\end{array}$ & $\begin{array}{l}\mathrm{LCR} \leq 8780 \\
(\mathrm{n}=21)\end{array}$ & $P$-value \\
\hline $\operatorname{im}(-/+)$ & $24 / 0$ & $16 / 5$ & $<0.01$ \\
\hline Stage (I, II / III, IV) & $11 / 13$ & $2 / 19$ & $<0.01$ \\
\hline $\mathrm{CEA}(<10 / \geq 10 \mathrm{ng} / \mathrm{mL})$ & $20 / 4$ & $16 / 5$ & 0.55 \\
\hline CA19-9 (< $100 / \geq 100 \mathrm{U} / \mathrm{mL})$ & $15 / 9$ & $10 / 11$ & 0.32 \\
\hline \multicolumn{4}{|c|}{$\begin{array}{l}\text { ANC, absolute neutrophil count; CA19-9, carbohydrate antigen } 19-9 \text {; CEA, carcinoembryonic antigen } \\
\text { CRP, C-reactive protein; HBV, hepatitis B virus; HCV, hepatitis C virus; im, intrahepatic metastasis; LCR, } \\
\text { lymphocyte-CRP ratio; LMN, lymph node metastasis; NLR, neutrophil-lymphocyte ratio; TLC, total } \\
\text { lymphocyte count; vp, portal vein invasion; vv, hepatic vein invasion. }\end{array}$} \\
\hline
\end{tabular}

Five-year OS rates after hepatectomy were significantly worse in the $\mathrm{LCR}^{\mathrm{Low}}$ group (15.2\%) than in the $\mathrm{LCR}^{\text {High }}$ group (57.5\%; $\mathrm{P}<0.01$; Fig. 3a). In univariate analysis, advanced disease stage (III/IV), lymph node metastasis (LNM), low LCR, and high CA19-9 were associated with worse OS. In multivariate analysis, LNM, low LCR, and high CA19-9 were independent prognostic factors (Table 2). 
Table 2

Univariate and multivariate analysis for overall survival

\begin{tabular}{|c|c|c|c|c|}
\hline \multirow[t]{2}{*}{ Variables } & \multirow[t]{2}{*}{ 5-year OS (\%) } & \multirow{2}{*}{$\begin{array}{l}\text { Univariate } \\
\text { P-value }\end{array}$} & \multicolumn{2}{|l|}{ Multivariate } \\
\hline & & & $\mathrm{HR}(95 \% \mathrm{Cl})$ & $P$-value \\
\hline \multicolumn{5}{|l|}{ Host factors } \\
\hline Age (<75 / $\geq 75 y)$ & $43.6 / 28.6$ & 0.11 & & \\
\hline Gender (M/F) & $39.1 / 32.5$ & 0.64 & & \\
\hline $\operatorname{NLR}(<2.24$ / $\geq 2.24)$ & $59.5 / 24.1$ & 0.09 & & \\
\hline LCR (> 8780 / $\leq 8780)$ & $57.5 / 15.2$ & $<0.01$ & $2.81(1.05-7.56)$ & 0.04 \\
\hline Frail $(-/+)$ & $40.4 / 36.9$ & 0.54 & & \\
\hline \multicolumn{5}{|l|}{ Tumor factors } \\
\hline Size $(<3 \mathrm{~cm} / \geq 3 \mathrm{~cm})$ & 47.6 / 37.6 & 0.95 & & \\
\hline LNM (- / +) & $40.8 / 18.3$ & 0.02 & $2.67(1.10-6.48)$ & 0.03 \\
\hline $\operatorname{vp}(-/+)$ & $46.6 / 16.9$ & 0.05 & & \\
\hline $\operatorname{vv}(-/+)$ & $38.4 / 20.0$ & 0.62 & & \\
\hline $\operatorname{im}(-/+)$ & $39.7 / 37.5$ & 0.74 & & \\
\hline Stage (I, II / III, IV) & $72.2 / 25.8$ & 0.01 & $1.71(0.49-5.89)$ & 0.39 \\
\hline CEA $(<10 / \geq 10 \mathrm{ng} / \mathrm{mL})$ & 40.4 / 33.3 & 0.73 & & \\
\hline CA19-9 $(<100 / \geq 100 \mathrm{U} / \mathrm{mL})$ & $57.7 / 15.2$ & $<0.01$ & $3.45(1.33-9.00)$ & 0.01 \\
\hline \multicolumn{5}{|c|}{$\begin{array}{l}\text { ANC, absolute neutrophil count; CA19-9, carbohydrate antigen } 19 \text { - 9; CEA, carcinoembryonic antigen; } \\
\text { CRP, C-reactive protein; im, intrahepatic metastasis; LCR, lymphocyte-CRP ratio; LMN, lymph node } \\
\text { metastasis; NLR, neutrophil-lymphocyte ratio; TLC, total lymphocyte count; vp, portal vein invasion; vv, } \\
\text { hepatic vein invasion. }\end{array}$} \\
\hline
\end{tabular}

Three-year DFS rates after hepatectomy were also significantly worse in the LCR ${ }^{\text {Low }}$ group ( $\left.0 \%\right)$ than in the LCR ${ }^{\text {High }}$ group (31.8\%; Fig. 3b). Univariate analysis associated age $\geq 75$ years old, advanced disease stage, LNM, portal vein invasion, and low LCR with poor prognosis, but none of these factors were found to be independent prognostic factors in multivariate analysis (Table 3 ). 
Table 3

Univariate and multivariate analysis for disease-free survival

\begin{tabular}{|c|c|c|c|c|}
\hline \multirow[t]{2}{*}{ Variables } & \multirow[t]{2}{*}{ 5-year OS (\%) } & \multirow{2}{*}{$\begin{array}{l}\text { Univariate } \\
\text { P-value }\end{array}$} & \multicolumn{2}{|l|}{ Multivariate } \\
\hline & & & $\mathrm{HR}(95 \% \mathrm{Cl})$ & $P$-value \\
\hline \multicolumn{5}{|l|}{ Host factors } \\
\hline Age (<75 / $\geq 75 y)$ & $28.0 / 0$ & 0.02 & $1.12(0.38-3.34)$ & 0.83 \\
\hline Gender (M/F) & $20.8 / 20.0$ & 0.84 & & \\
\hline $\operatorname{NLR}(<2.24$ / $\geq 2.24)$ & $21.7 / 20.0$ & 0.83 & & \\
\hline LCR (> 8780 / $\leq 8780)$ & $31.8 / 0$ & $<0.01$ & $1.87(0.68-5.18)$ & 0.23 \\
\hline Frail $(-/+)$ & 27.3 / 9.1 & 0.21 & & \\
\hline \multicolumn{5}{|l|}{ Tumor factors } \\
\hline Size $(<3 \mathrm{~cm} / \geq 3 \mathrm{~cm})$ & $30.0 / 16.7$ & 0.10 & & \\
\hline LNM (- / +) & $27.0 / 0$ & 0.02 & $1.65(0.62-4.41)$ & 0.32 \\
\hline $\operatorname{vp}(-/+)$ & $26.1 / 9.1$ & 0.04 & $1.36(0.48-3.87)$ & 0.57 \\
\hline $\operatorname{vv}(-/+)$ & $20.7 / 25.0$ & 0.48 & & \\
\hline $\operatorname{im}(-/+)$ & $22.6 / 0$ & 0.28 & & \\
\hline Stage (I, II / III, IV) & $54.6 / 4.4$ & $<0.01$ & $2.64(0.70-9.92)$ & 0.15 \\
\hline CEA $(<10 / \geq 10 \mathrm{ng} / \mathrm{mL})$ & $21.5 / 20.0$ & 0.85 & & \\
\hline CA19-9 $(<100 / \geq 100 \mathrm{U} / \mathrm{mL})$ & $28.6 / 8.3$ & 0.22 & & \\
\hline \multicolumn{5}{|c|}{$\begin{array}{l}\text { ANC, absolute neutrophil count; CA19-9, carbohydrate antigen } 19 \text { - 9; CEA, carcinoembryonic antigen; } \\
\text { CRP, C-reactive protein; im, intrahepatic metastasis; LCR, lymphocyte-CRP ratio; LMN, lymph node } \\
\text { metastasis; NLR, neutrophil-lymphocyte ratio; TLC, total lymphocyte count; vp, portal vein invasion; vv, } \\
\text { hepatic vein invasion. }\end{array}$} \\
\hline
\end{tabular}

\section{Preoperative LCR levels can reflect numbers of local tumor CD8 ${ }^{+}$TILs}

The median percentages of TILs were $0.39 \%$ (interquartile range [IQR]: $0.23-0.97$ ) in the LCR ${ }^{\text {High }}$ group, and $0.45 \%$ (IQR: $0.26-0.61$ ) in the LCR ${ }^{\text {Low }}$ group. (Fig. 4a) LCR and stromal TILs were not significantly associated.

The median numbers of CD8 ${ }^{+}$TILs were 21.3 /slide (IQR: 12.3-34.7) in the LCR $^{\text {High }}$ group, and 12.8 /slide (IQR: 6.7-15.9) in the LCR ${ }^{\text {Low }}$ group (Fig. 4b). The number of CD8 ${ }^{+}$TILs was related to LCR $(P=0.0481)$. 


\section{Discussion}

The present study suggests that preoperative LCR can indicate the postsurgical prognosis for patients who undergo resection for IHCC. Furthermore, as LCR was associated with CD $8^{+}$TILs, it indirectly reflects local tumor immune activity. This is the first report to find a correlation between a systemic immune marker and $\mathrm{CD} 8^{+}$TILs in patients with IHCC.

LCR is already reported to be a prognostic marker for colorectal, gastric, pancreatic, and breast cancers [17-21]. For patients with IHCC who undergo curative resection, NLR, LMR, PLR, and SII are reportedly significant prognostic factors [4, 9-11]. Many papers have especially suggested NLR as a strong prognostic marker for IHCC. In our result, NLR tended to be a prognostic factor in OS, but not significantly so, whereas LCR was found to be an independent prognostic factor. LCR may be stronger prognostic factor than NLR in this setting.

LCR is the combination of TLC and CRP. CRP is a well-established marker for inflammation. Elevated preoperative CRP level is widely reported to be associated with poor prognosis in various cancers, including IHCC [30-32]. CRP is synthesized by hepatocytes in response to IL-6, TNF and IL-1 $\beta$, which can activate cancer cell proliferation. CRP may reflect systemic inflammation, and cancer cell proliferation and protection from apoptosis. [33, 34]. TLC also reflect host immune status; several papers have associated low TLC with poor prognosis $[35,36]$.

However, the mechanism that links LCR to patients' long-term prognosis has been unclear. In the present study, we focused on the relationship between LCR and TILs, which are indicators of local tumor immunity. TILs have attracted recent attention with the development of immune checkpoint inhibitors. In addition, there were some reports TILs had the relationship between peripheral blood cells, such as TLC and absolute neutrophil count (ANC) $[23,24]$.

Interestingly, although this study found no significant relationship between LCR and stromal TILs, LCR and CD8 ${ }^{+}$TILs, specifically, were associated. TILs volume is reportedly correlated with tumor mutation burden (TMB) [37]. TMB is the number of gene mutations cancer cells have, and is associated with predicted immunotherapy response [38]. In breast cancer, which is reported to have relatively high TMB and TILs, patients who have more than $50 \%$ TILs are often defined as LPBC; $<10 \%$ TILs are considered minimal [28]. In the present study, the median TIL percentage in all patients was $0.43 \%$ (IQR: 0.26-0.77), which was much lower than for breast cancer. Biliary cancer is also reported to have relatively low TMB [39]. Thus, TILs in IHCC were expected to be low, and our result was consistent with that. Low TIL percentage in IHCC may be why LCR and TILs did not correlate. Furthermore, the TIL evaluation method included all mononuclear cells-not only lymphocyte. As IHCC apparently has low TILs, possibly cells other than lymphocytes were affected.

TILs include various types of lymphocytes, such as $\mathrm{CD}^{+}, \mathrm{CD} 4^{+}, \mathrm{CD} 8^{+}$cells; $\mathrm{CD} 8^{+} \mathrm{T}$ cells are considered especially important among them. Tumor infiltration by $\mathrm{CD}^{+} \mathrm{T}$ cells has been strongly associated with 
survival of cancer patients $[26,28]$. Yoshida et al. also reported that CRP inhibited proliferation, activation, and function of $\mathrm{CD} 8^{+} \mathrm{T}$ cells in patients with melanoma [40]. Thus, CD8 ${ }^{+}$TILs may be more strongly associated with LCR, which is a robust prognostic factor.

This study had several limitations. First, it is a retrospective analysis from a single center, with a relatively small study cohort. Second, although lymphocytes come in various types, we assessed only CD8 ${ }^{+} \mathrm{T}$ cells. A larger study, and an assessment of non-CD8 $8^{+}$lymphocytes are issues for the future.

\section{Conclusions}

In conclusion, LCR can predict prognosis of patients with IHCC via correlation with CD8 ${ }^{+}$TILs.

\section{List Of Abbreviations}

absolute neutrophil count: ANC

apparent diffusion coefficient: ADC

computed tomography: CT

C-reactive protein: CRP

disease-free survival: DFS

F-box and WD repeat domain-contain 7: FBXW7

hematoxylin and eosin: H.E

hepatocellular carcinoma: HCC

intrahepatic cholangiocarcinoma: IHCC

intrahepatic metastasis: im

lymphocyte-C-reactive protein ratio: LCR

lymphocyte-monocyte ratio: LMR

lymph node metastasis: LNM

Lymphocyte-predominant breast cancer: LPBC

magnetic resonance imaging: MRI

modified Glasgow Prognostic Score: mGPS 
neutrophil-lymphocyte ratio: NLR

overall survival: OS

platelet-lymphocyte ratio: PLR

prognostic nutrition index: PNI

programmed death ligand 1: PD-L1

receiver operating characteristics: ROC

Secreted Frizzled-Related Protein-1: SFRP1

systemic immune inflammation index: SII

total lymphocyte count: TLC

tumor-infiltrating lymphocytes: TILs

tumor mutation burden: TMB

portal vein invasion: vp

hepatic vein invasion: vv

\section{Declarations}

\section{Ethics approval and consent to participate}

This study was approved by Tokushima University Hospital ethics committee and with the approval of corresponding regulatory agencies, and all the experiments were carried out in accordance with the approved guidelines (Tokushima Clinical Trial Management System Number; 3215).

\section{Consent for publication}

All the patients involved in this study signed informed consent forms and agreed to participate.

\section{Availability of data and material}

The datasets used and analyzed during the current study are available from the corresponding author on reasonable request.

\section{Competing interests}

The authors declare that they have no competing interests. 


\section{Funding}

Not applicable.

\section{Authors' contributions}

1. KM participated in the research design, performance of the research, data analysis and writing manuscripts.

2. YM participated in the research design, performance of the research.

3. SI participated in performance of the research.

4. TI participated in performance of the research.

5. YS participated in performance of the research.

6. SY participated in performance of the research.

7. KT participated in performance of the research.

8. SO participated in performance of the research.

9. SY participated in performance of the research.

10. TO participated in performance of the research, and pathological assessment.

11. KT participated in performance of the research, and pathological assessment.

12. MS participated in the critical comments and administrative support.

\section{Acknowledgement}

Not applicable.

\section{References}

1. Aishima S, Kuroda Y, Nishihara Y, et al. Proposal of progression model for intrahepatic cholangiocarcinoma: clinicopathologic differences between hilar type and peripheral type. Am J Surg Pathol. 2007; 31: 1059-67.

2. Mavros MN, Economopoulos KP, Alexiou VG, et al. Treatment and prognosis for patients with intrahepatic cholangiocarcinoma: systematic review and meta-analysis. JAMA Surg. 2014; 149(6): 565-74.

3. Ishikawa D, Nishi M, Takasu C, et al. The role of neutrophil-to-lymphocyte ratio on the effect of CRT for patients with rectal cancer. In Vivo. 2020; 34: 863-68

4. Lin G, Liu Y, Li S, et al. Elevated neutrophil-to-lymphocyte ratio is an independent poor prognostic factor in patients with intrahepatic cholangiocarcinoma. Oncotarget. 2016; 7(32): 50963-71.

5. Mcmilan DC, Crozier JE, Canna K, et al. Evaluation of an inflammation-based prognostic score (GPS) in patients undergoing resection for colon and rectal cancer. Int $J$ Colorectal Dis. 2007; 22: 881-86. 
6. Okuno M, Ebata T, Yokoyama $Y$, et al. Appraisal of inflammation-based prognostic scores in patients with unresectable perihilar cholangiocarcinoma. J Hepatobiliary Pancreat Sci. 2016; 23(10): 636-42.

7. Chan AW, Chan SL, Wong GL, et al. Prognostic nutritional index『PNI『predicts tumor recurrence of very early / early stage hepatocellular carcinoma after surgical resection. Ann Surg Oncol. 2015; 22: 4138-48.

8. Akgül Ö, Bagante F, Olsen G, et al. Preoperative prognostic nutritional index predicts survival of patients with intrahepatic cholangiocarcinoma after curative resection. J Surg Oncol. 2018; 118(3): 422-30

9. Chen Q, Dai Z, Yin D, et al. Negative impact of preoperative platelet-lymphocyte ratio on outcome after hepatic resection for intrahepatic cholangiocarcinoma. Medicine (Baltimore). 2015; 94(13): e574.

10. Tsiimigras $D$, Moris $D$, Mehta $R$, et al. The systemic immune-inflammation index predicts prognosis in intrahepatic cholangiocarcinoma: an international multi-institutional analysis. HBP (Oxford). 2020; S1365-182X(20): 30093-9.

11. Wu Y, Ren F, Chai Y, et al. Prognostic value of inflammation-based indexes for intrahepatic cholangiocarcinoma following curative resection. Oncol Lett. 2019; 17(1): 165-174.

12. Kawashita Y, Morine Y, Saito Y, et al. Role of heat shock factor 1 expression in the microenvironment of intrahepatic cholangiocarcinomas. J Gastroenterol Hepatol. 2018; 33(7): 1407-12.

13. Davaadorj M, Saito Y, Morine Y, et al. Loss of Secreted Frizzled-Related Protein-1 expression is associated with poor prognosis in intrahepatic cholangiocarcinoma. Eur J Surg Oncol. 2017; 43(2): 344-50.

14. Enkbold C, Utsunomiya T, Morine Y, et al. Loss of FBXW7 expression is associated with poor prognosis in intrahepatic cholangiocarcinoma. Hepatol Res. 2014; 44(14):E346-52.

15. Yamada S, Morine Y, Imura S, et al. Prognostic prediction of apparent diffusion coefficient obtained by diffusion-weighted MRI in mass-forming intrahepatic cholangiocarcinoma. J Hepatobiliary Pancreat Sci. 2020; 27(7): 388-95.

16. Teraoku H, Morine $\mathrm{Y}$, Uyama N, et al. Role of Central Hypo-enhancement in the Hepatic Arterial Phase of Dynamic Computed Tomography in Patients with Mass-Forming Intrahepatic Cholangiocarcinoma. World J Surg. 2020; 44(7): 2350-8.

17. Okugawa $Y$, Toiyama $Y$, Yamamoto A, et al. Lymphocyte-C-reactive protein ratio as promising new marker for predicting surgical and oncological outcomes in colorectal cancer. Ann Surg. 2020; 272(2): 342-51.

18. Okugawa $Y$, Toiyama $Y$, Yamamoto A, et al. Lymphocyte-to-C-reactive protein ratio and score are clinically feasible nutrition-inflammation markers of outcome in patients with gastric cancer. Clin Nutr. 2020; 39(4): 1209-17.

19. Fan Z, Luo G, Gong Y, et al. Prognostic value of the C-reactive protein/lymphocyte ratio in Pancreatic Cancer. Ann Surg Oncol. 2020; 
20. Okugawa $\mathrm{Y}$, Toiyama $\mathrm{Y}$, Fujikawa $\mathrm{H}$, et al. Prognostic potential of lymphocyte-C-reactive protein ratio in patients with rectal cancer receiving preoperative chemoradiotherapy. J Gastrointest Surg. [online ahead of print.2020] doi: 10.1007/s11605-019-04495-4.

21. Sata A, Fukui R, Miyagawa Y, et al. C-reactive protein and absolute lymphocyte count can predict overall survival of patients treated with eribulin. Anticancer Res. 2020; 40(7): 4147-56.

22. Ohtani H, Mori K, Nakajima M, et al. Defining lymphocyte-predominant breast cancer by the proportion of lymphocyte-rich stroma and its significance in routine histopathological diagnosis. Pathol Int. 2015; 65(12): 644-51.

23. Lee $\mathrm{YY}$, $\mathrm{Choi} \mathrm{CH}$, Sung $\mathrm{CO}$, et al. Clinical significance of changes in peripheral lymphocyte count after surgery in early cervical cancer. Gynecol Oncol. 2012; 127(1): 107-13.

24. Yoon $\mathrm{Cl}$, Park $\mathrm{S}$, Cha YJ, et al. Associations between absolute neutrophil count and lymphocytepredominant breast cancer. Breast. 2020; 50: 141-8.

25. Zhu Y, Wang XY, Zhang Y, et al. Programmed death ligand 1 expression in human intrahepatic cholangiocarcinoma and its association with prognosis and CD8+ T-cell immune responses. Cancer Manag Res. 2018; 2; 10: 4113-23.

26. Asahi Y, Hatanaka K, Hatanaka Y, et al. Prognostic impact of CD8+ T cell distribution and its association with the HLA class I expression in intrahepatic cholangiocarcinoma. Surg Today. 2020; 50(8): 931-40.

27. Morine $Y$, Shimada $M$. The value of systematic lymph node dissection for intrahepatic cholangiocarcinoma from the viewpoint of liver lymphatics. J Gastroenterol. 2015; 50(9): 913-27.

28. SalgadoP R, Denkert C, Demaria $S$, et al. The evaluation of tumor-infiltrating lymphocytes (TILs) in breast cancer: recommendations by an International TILs Working Group 2014. Ann Oncol. 2015; 26(2): 259-71.

29. Ishikawa D, Shimada M, Utsunomiya T, et al. Effect of Twist and Bmi1 on intraductal papillary mucinous neoplasm of the pancreas. J Gastroenterol Hepatol 2014; 29(12): 2032-7.

30. T, Milz S, Schepke M, et al. C-reactive protein is a prognostic indicator in patients with perihilar cholangiocarcinoma. World J Gastroenterol. 2006; 14; 12(34): 5495-500.

31. Nozoe T, Iguchi T, Adachi E, et al. Preoperative elevation of serum C-reactive protein as an independent prognostic indicator for gastric cancer. Surg Today. 2011; 41(4): 510-3.

32. Kishi T, Nakamura A, Itasaka S, et al. Pretreatment C-reactive protein level predicts outcome and patterns of failure after chemoradiotherapy for locally advanced pancreatic cancer. Pancreatology. 2015; 15(6): 694-700.

33. Yang J, Wezeman $M$, Zhang $X$, et al. Human C-reactive protein binds activating Fcgamma receptors and protects myeloma tumor cells from apoptosis. Cancer Cell. 2007; 12(3): 252-65.

34. Yang J, Liu Z, Liu H, et al. C-reactive protein promotes bone destruction in human myeloma through the CD32-p38 MAPK-Twist axis. Sci Signal. 2017; 12; 10(509). 
35. Iseki $Y$, Shibutani $M$, Maeda $K$, et al. The impact of the preoperative peripheral lymphocyte count and lymphocyte percentage in patients with colorectal cancer. Surg Today. 2017; 47(6): 743-54

36. Liang L, Zhu J, Jia H, et al. Predictive value of pretreatment lymphocyte count in stage II colorectal cancer and in high-risk patients treated with adjuvant chemotherapy. Oncotarget. 2016; 5; 7(1): 101428.

37. Loupakis F, Depetris I, Biason P, et al. Prediction of Benefit from Checkpoint Inhibitors in Mismatch Repair Deficient Metastatic Colorectal Cancer: Role of Tumor Infiltrating Lymphocytes. Oncologist. 2020; 25(6): 481-7.

38. Ozaki Y, Muto S, Takagi H, et al. Prognostic Impact of Tumor Mutation Burden in Patients With Completely Resected Non-Small Cell Lung Cancer: Brief Report. J Thorac Oncol. 2018; 13(8): 121721.

39. Zehir A, Benayed R, Shah RH, et al. Mutational landscape of metastatic cancer revealed from prospective clinical sequencing of 10,000 patients. Nat Med 2017; 23(6): 703-13.

40. Yoshida T, Ichikawa J, Giuroiu I, et al. C reactive protein impairs adaptive immunity in immune cells of patients with melanoma. J Immunother Cancer. 2020; 8(1).

\section{Figures}




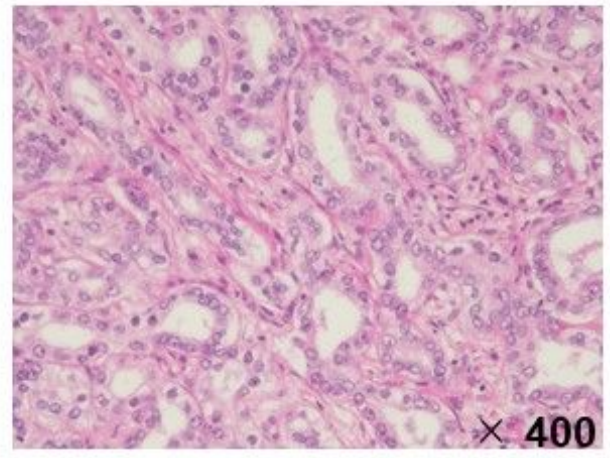

(a)
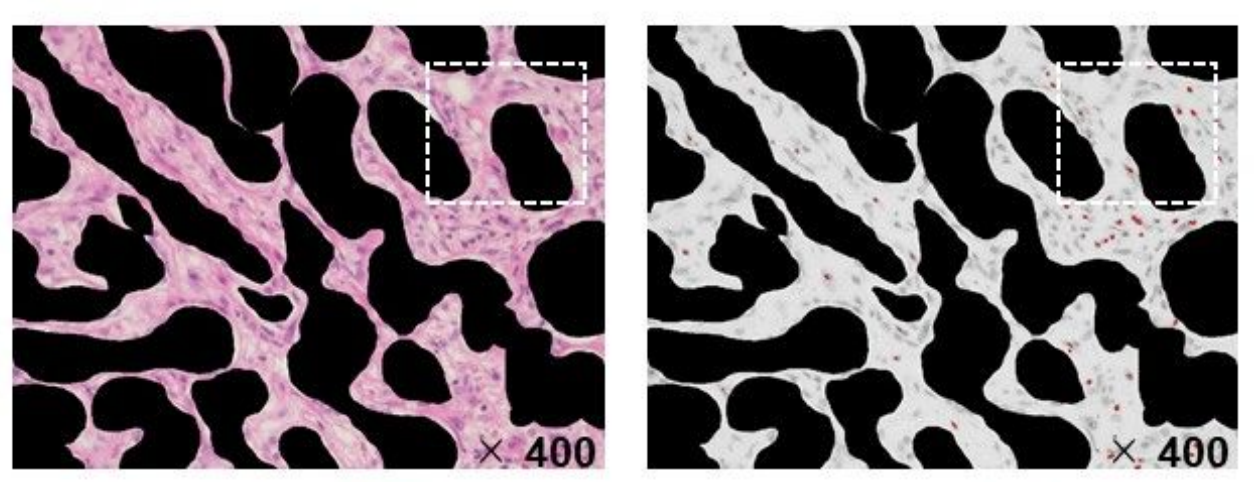

(b)

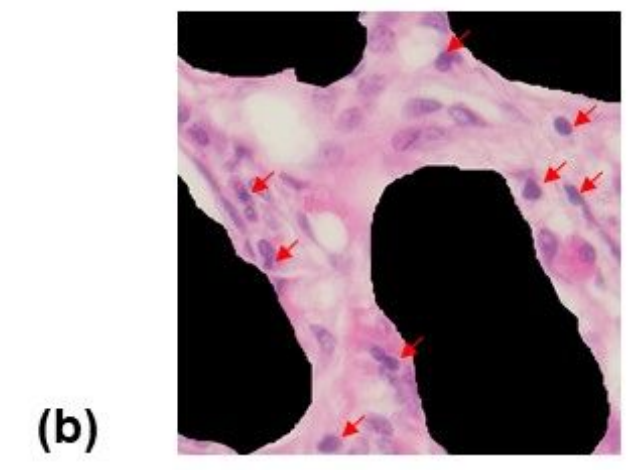

\section{Figure 1}

\section{Figure 1}

Method of assessing tumor-infiltrating leukocytes (TILs) using ImageJ. (a) For each patient, we selected 3 average regions in high-power fields (400x magnification); (b) excluded the tumor cells (black); and (c) calculated TILs as lymphocyte area (red) / stromal area (excluding black area), and averaged the score of TILs in the 3 fields. 

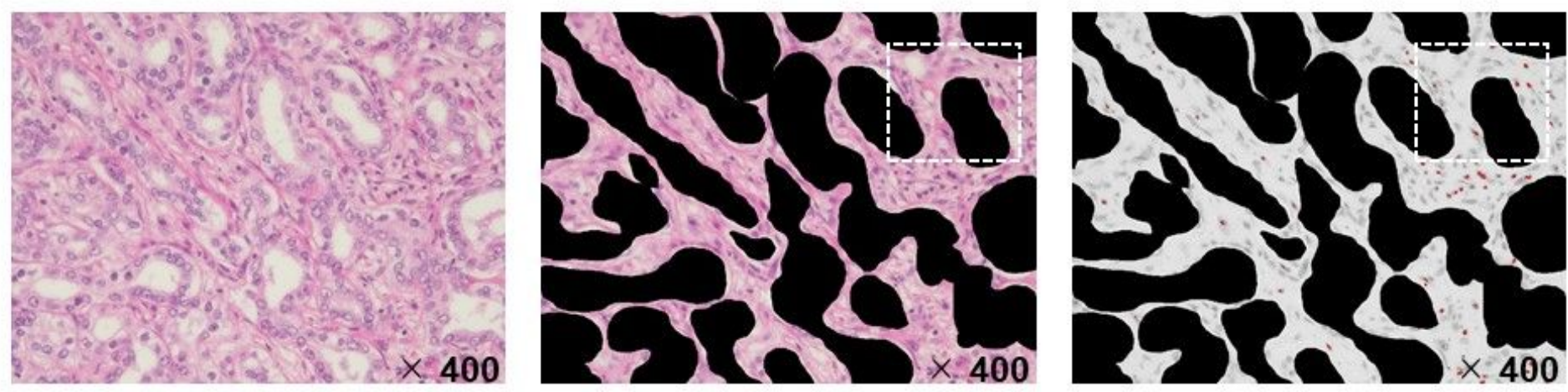

(a)

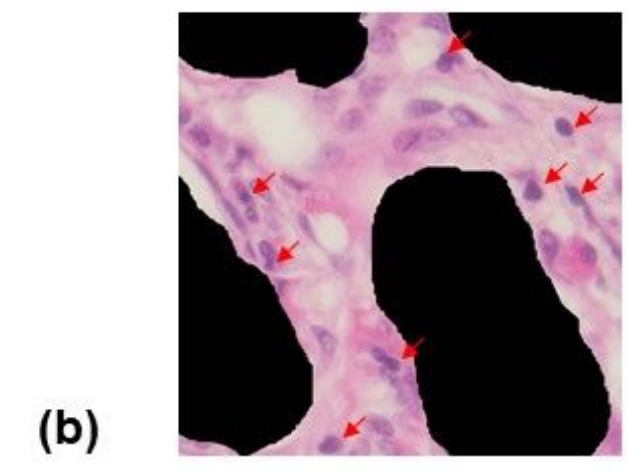

(b)

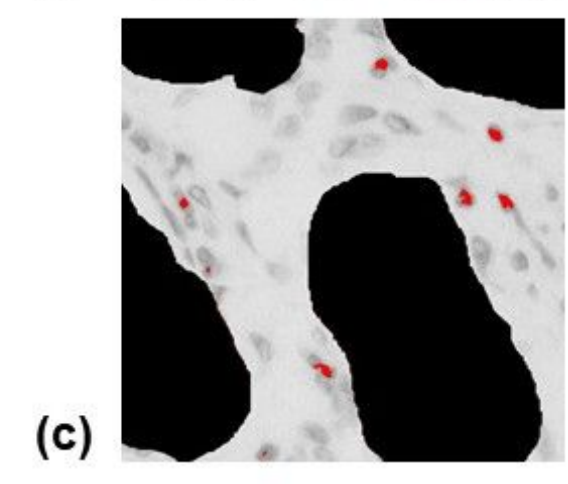

(c)

\section{Figure 1}

\section{Figure 1}

Method of assessing tumor-infiltrating leukocytes (TILs) using ImageJ. (a) For each patient, we selected 3 average regions in high-power fields (400x magnification); (b) excluded the tumor cells (black); and (c) calculated TILs as lymphocyte area (red) / stromal area (excluding black area), and averaged the score of TILs in the 3 fields. 

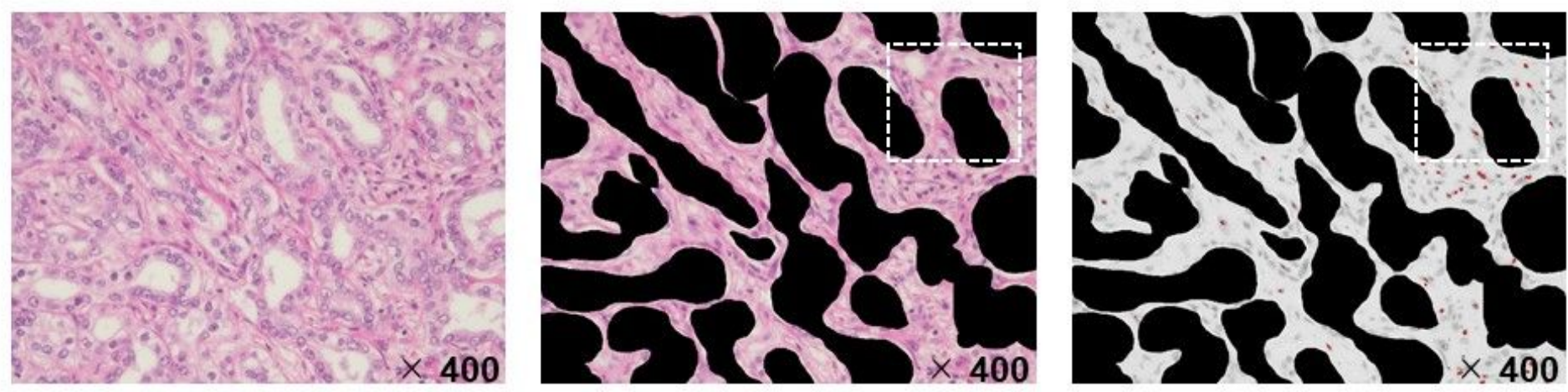

(a)

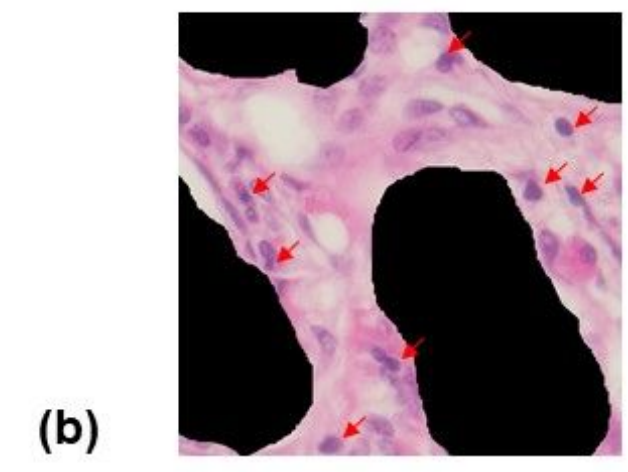

(b)

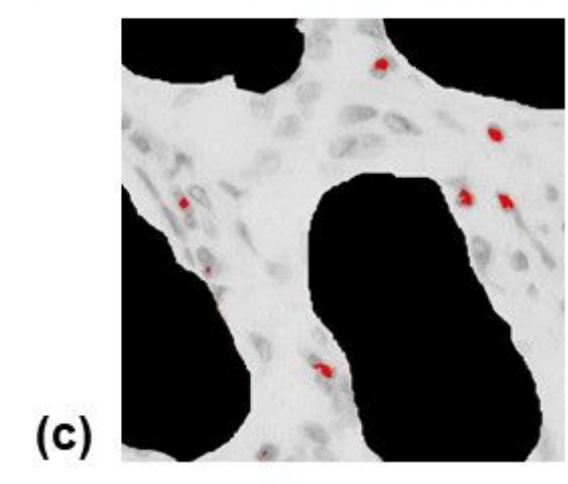

(c)

\section{Figure 1}

\section{Figure 1}

Method of assessing tumor-infiltrating leukocytes (TILs) using ImageJ. (a) For each patient, we selected 3 average regions in high-power fields (400x magnification); (b) excluded the tumor cells (black); and (c) calculated TILs as lymphocyte area (red) / stromal area (excluding black area), and averaged the score of TILs in the 3 fields. 


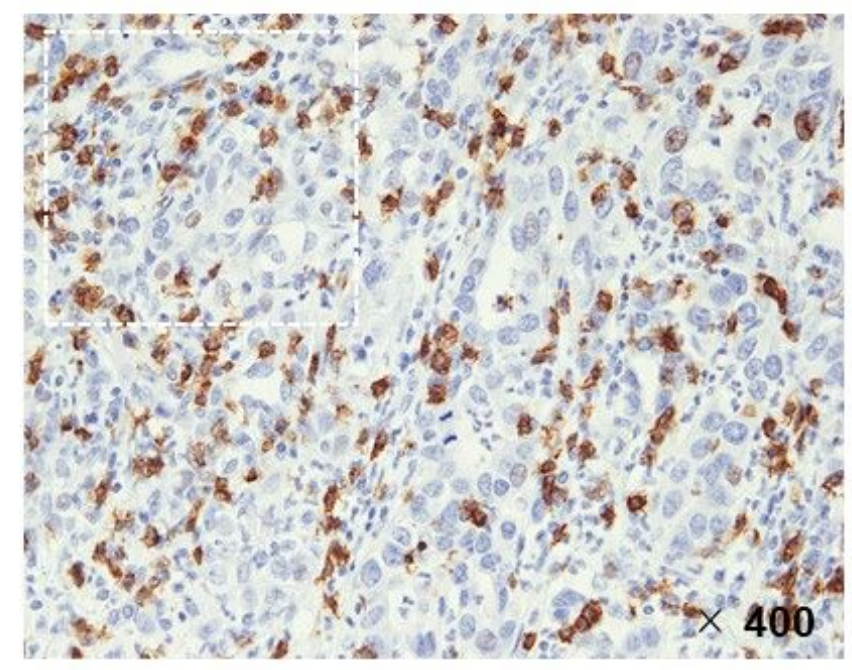

(a)

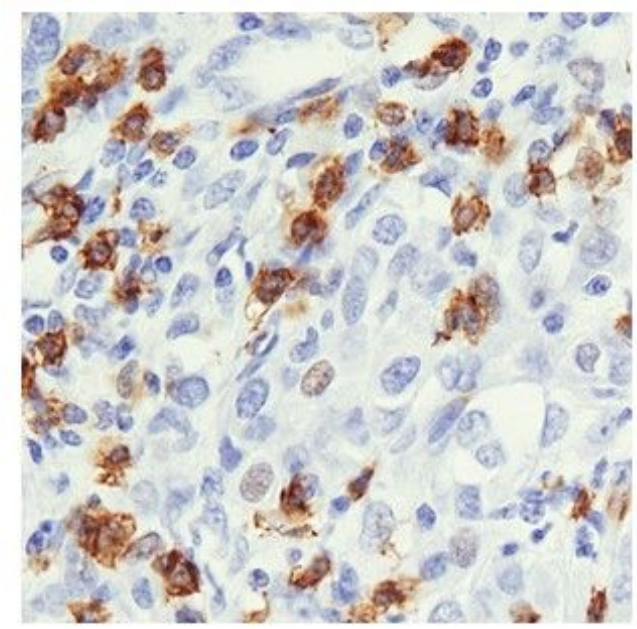

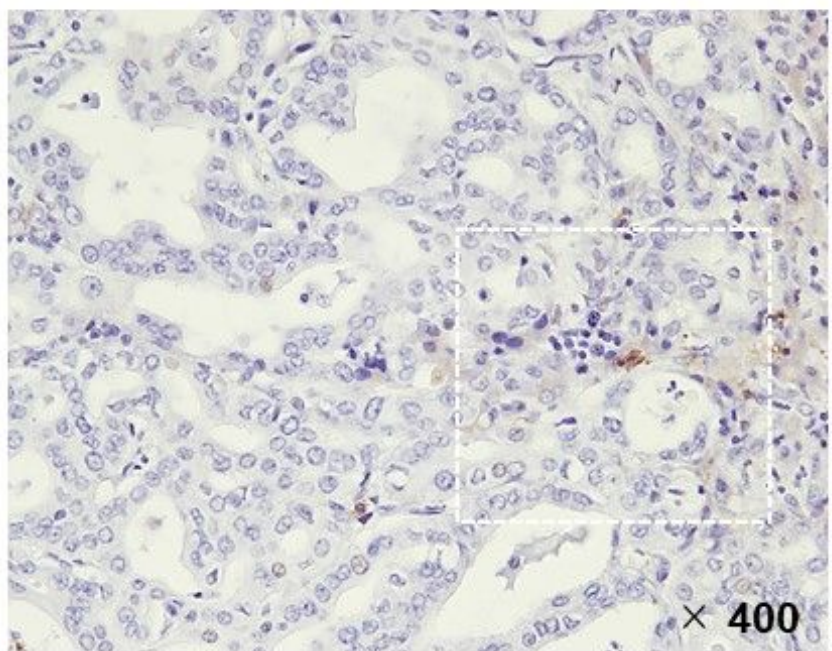

(b)

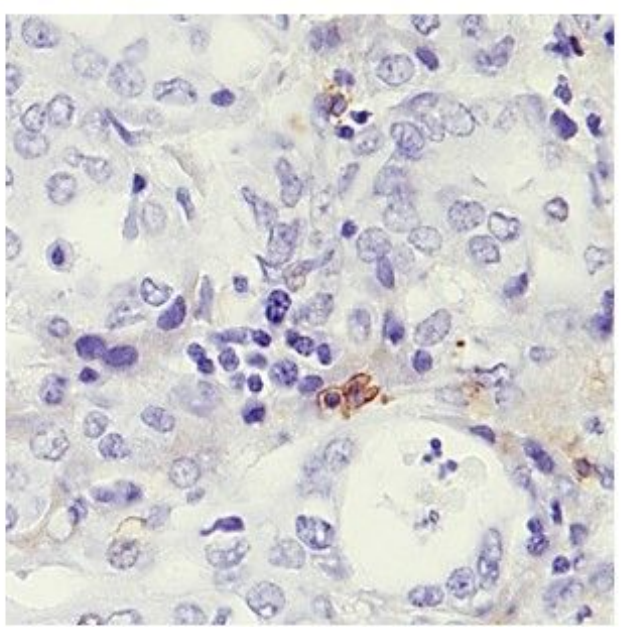

Figure 2

\section{Figure 2}

Immunohistochemical staining for CD8+ tumor-infiltrating leukocytes (TILs). (a) Low CD8+ TILs; (b) high CD8+ TILs. 


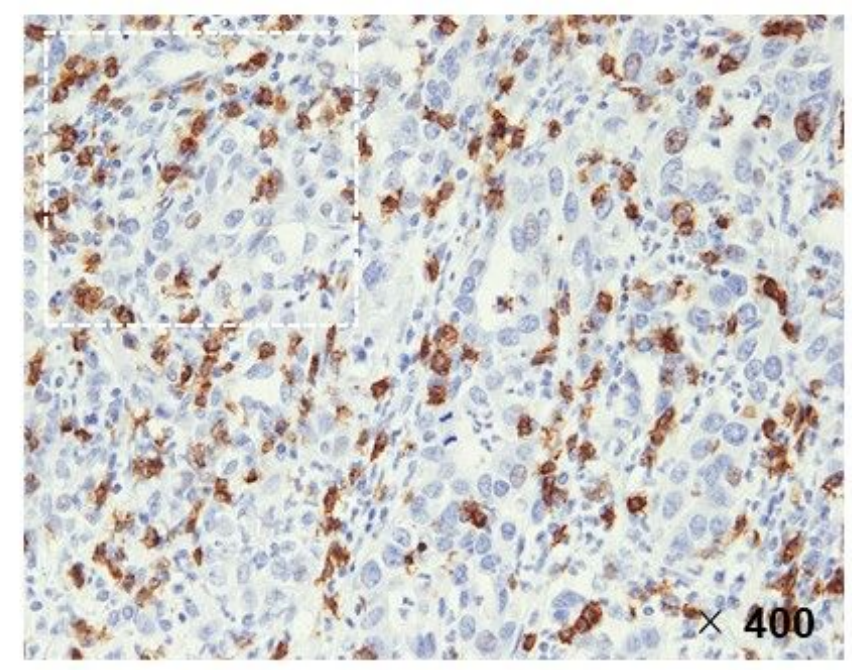

(a)

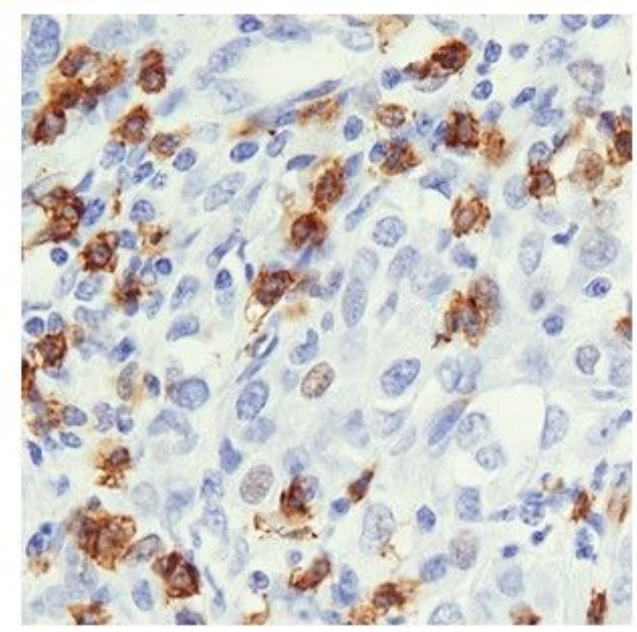

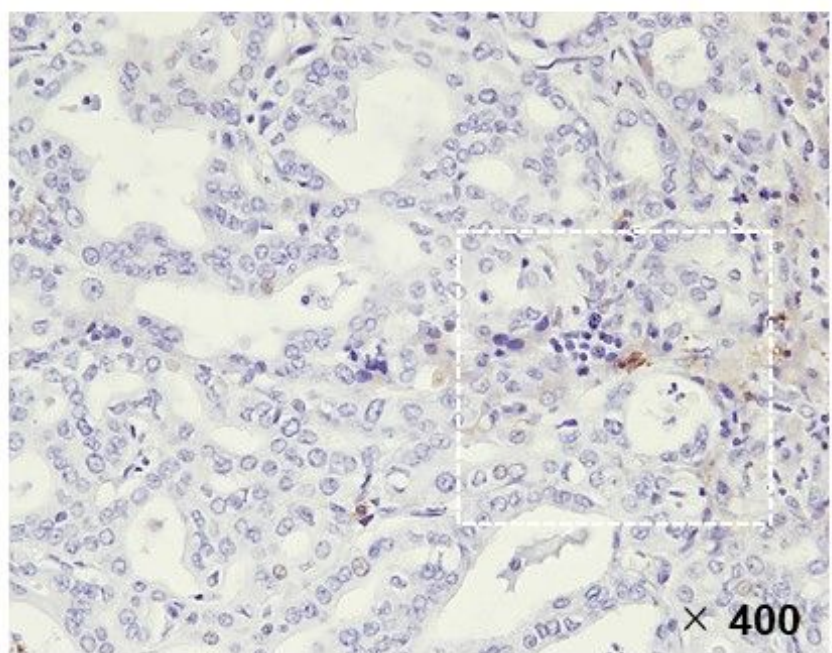

(b)

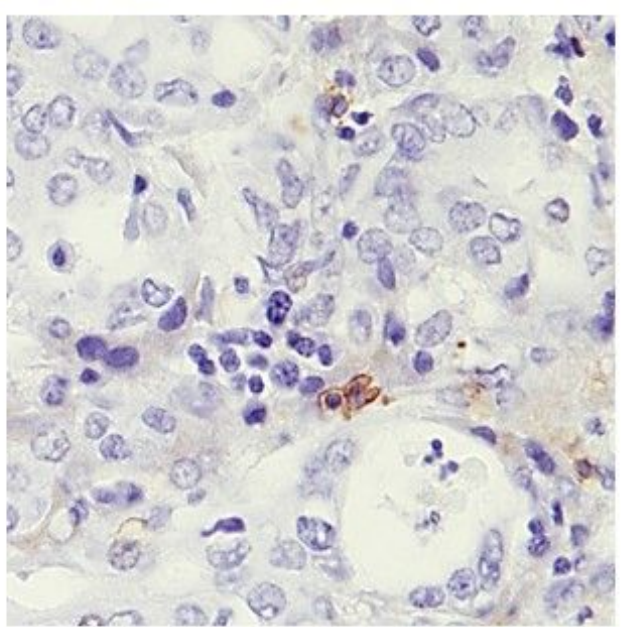

Figure 2

\section{Figure 2}

Immunohistochemical staining for CD8+ tumor-infiltrating leukocytes (TILs). (a) Low CD8+ TILs; (b) high CD8+ TILs. 


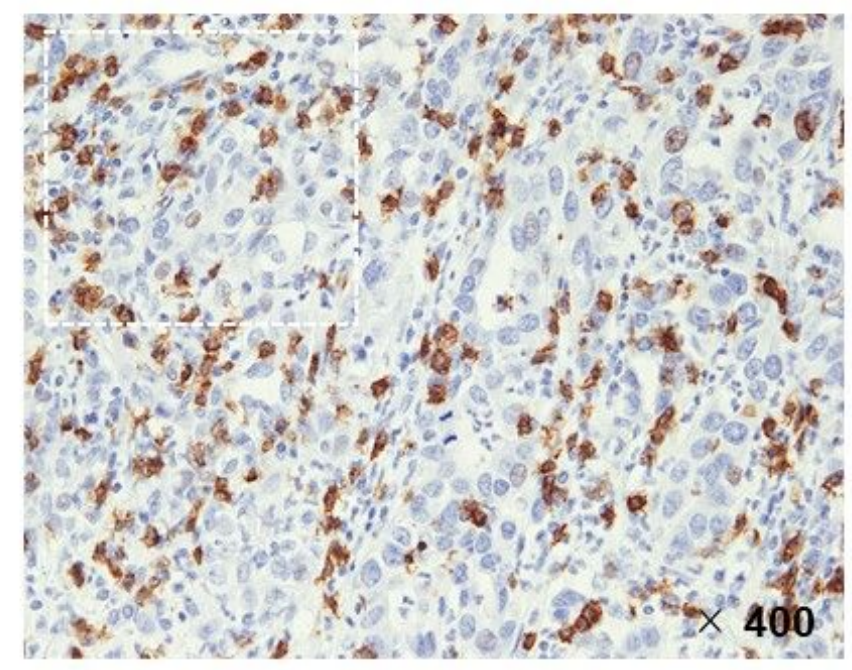

(a)

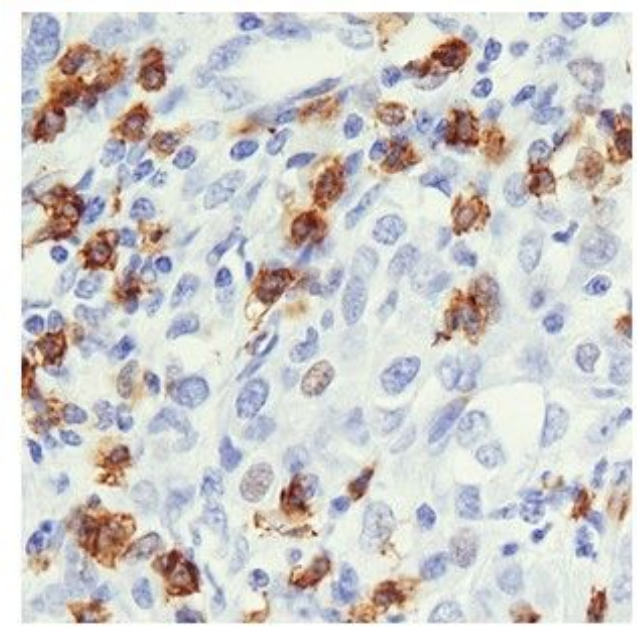

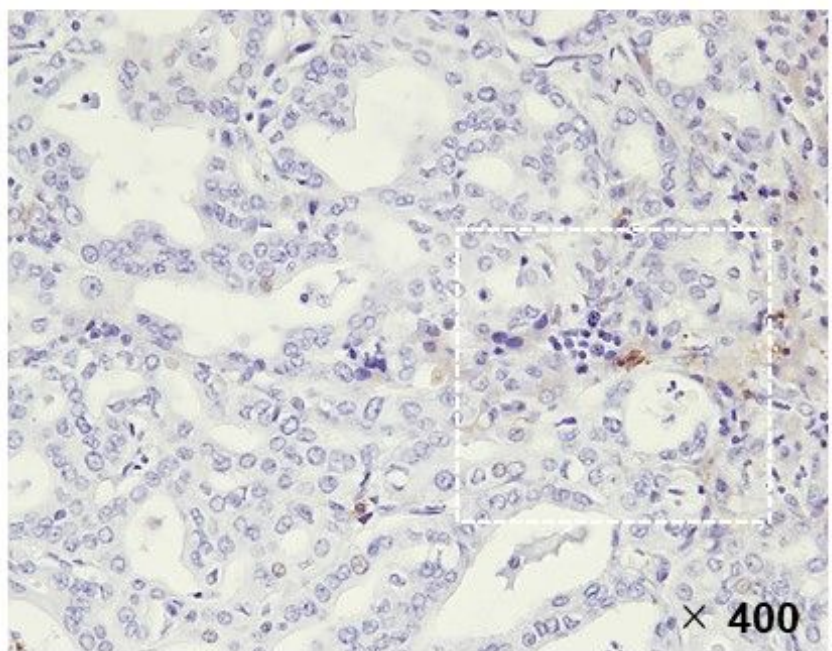

(b)

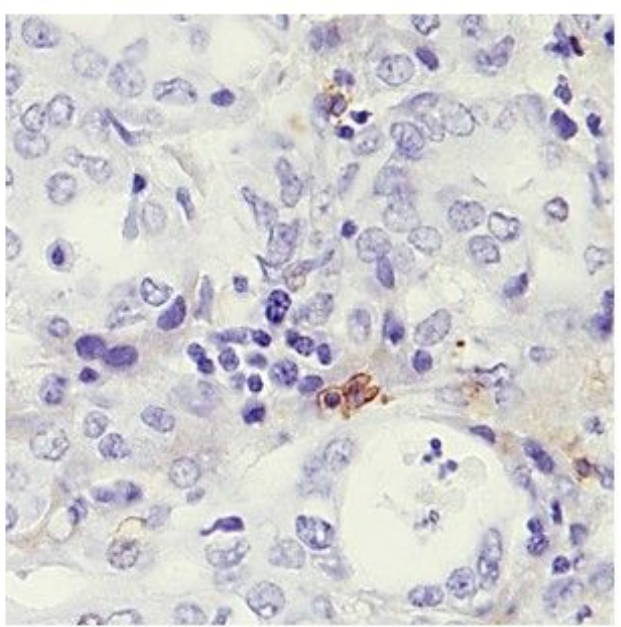

Figure 2

\section{Figure 2}

Immunohistochemical staining for CD8+ tumor-infiltrating leukocytes (TILs). (a) Low CD8+ TILs; (b) high CD8+ TILs. 


\section{Overall survival}

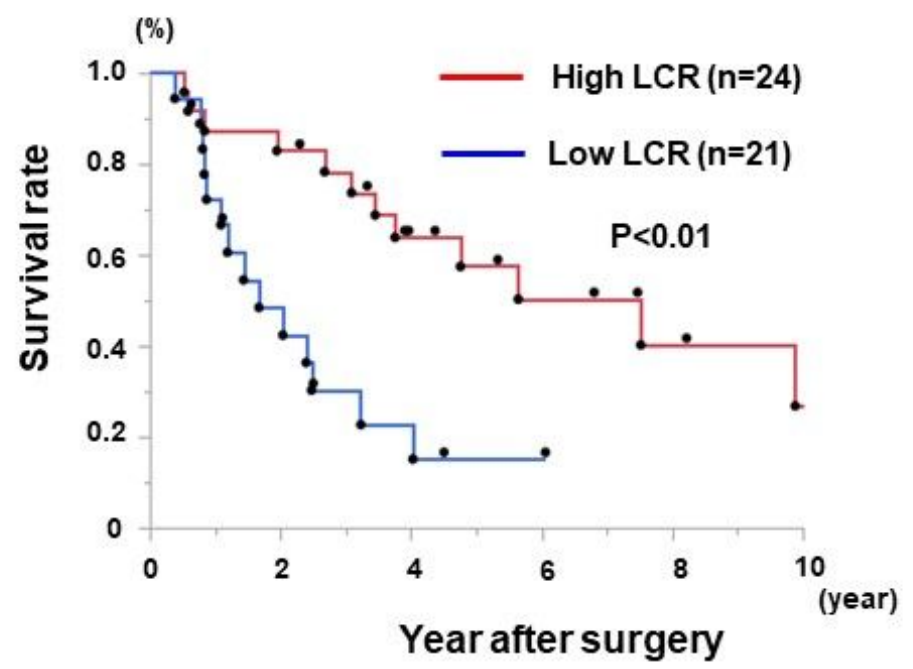

(a)
Disease-free survival

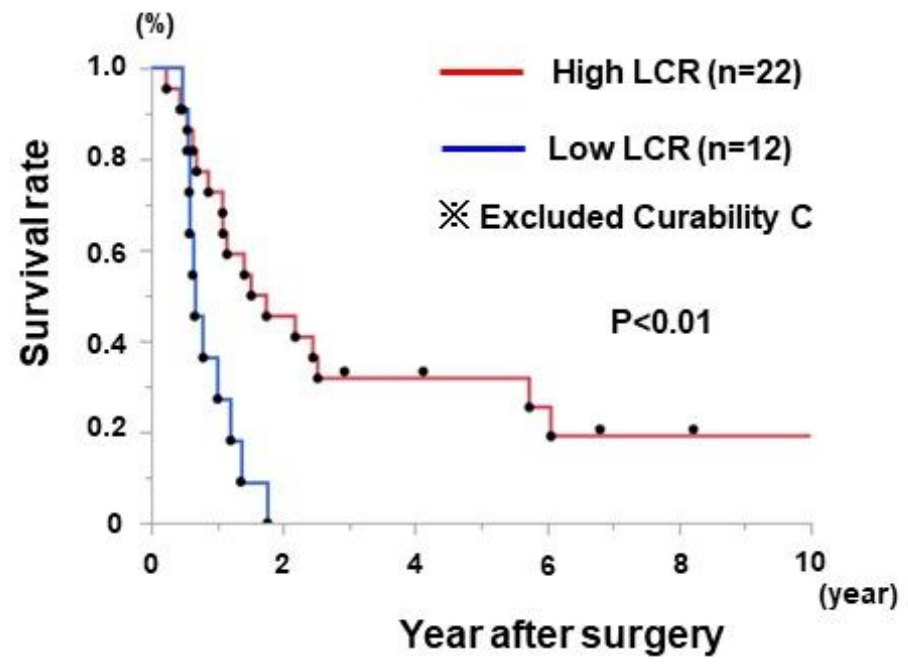

(b)

\section{Figure 3}

\section{Figure 3}

Survival curves. (a) Overall survival rates among patients with high or low lymphocyte/C-reactive protein ratio (LCR; $P<0.01)$. (b) Disease-free survival rate among patients with high or low $L C R(P<0.01)$ 


\section{Overall survival}

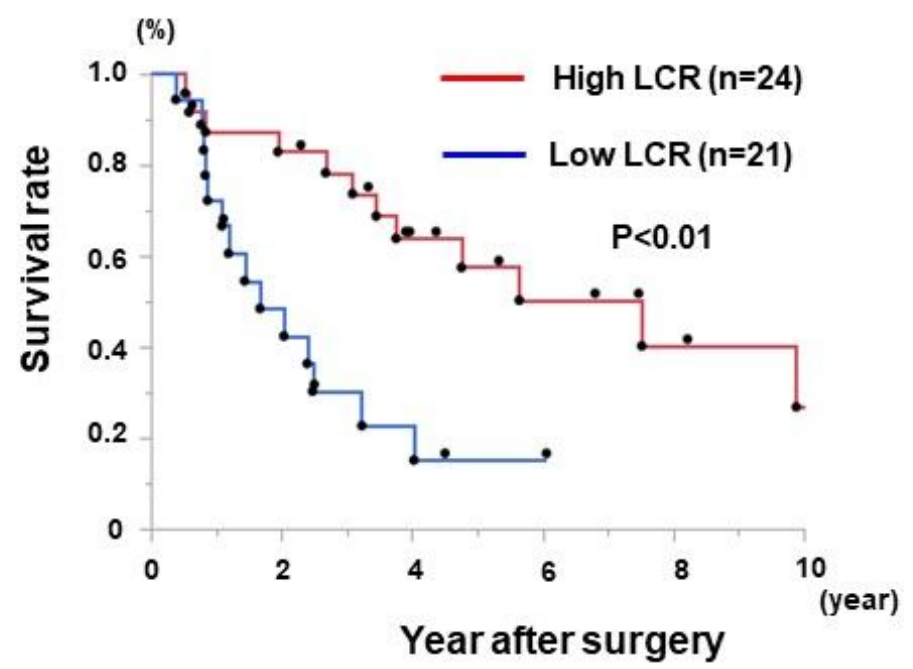

(a)
Disease-free survival

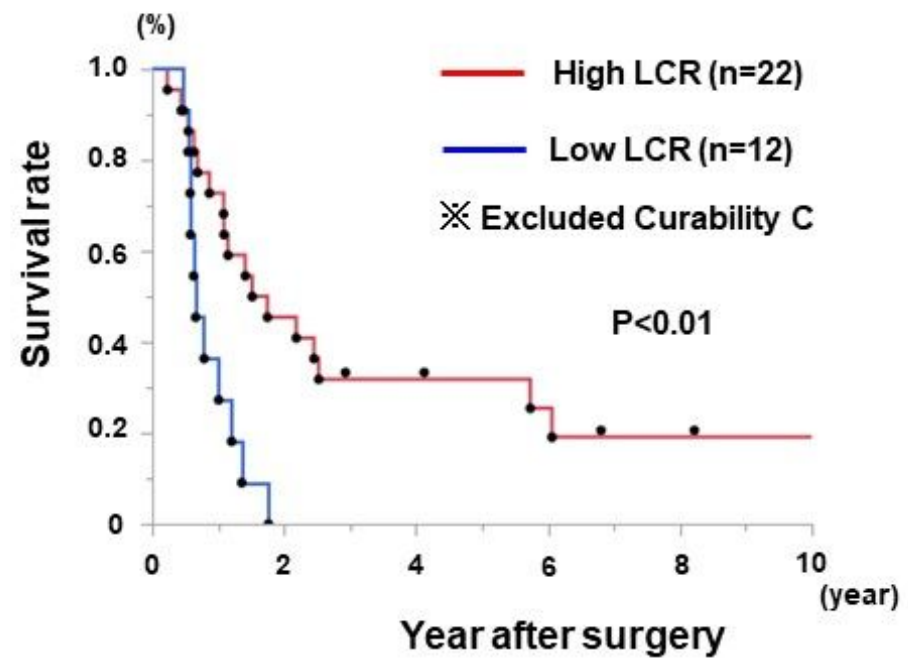

(b)

\section{Figure 3}

\section{Figure 3}

Survival curves. (a) Overall survival rates among patients with high or low lymphocyte/C-reactive protein ratio (LCR; $P<0.01)$. (b) Disease-free survival rate among patients with high or low $L C R(P<0.01)$ 


\section{Overall survival}

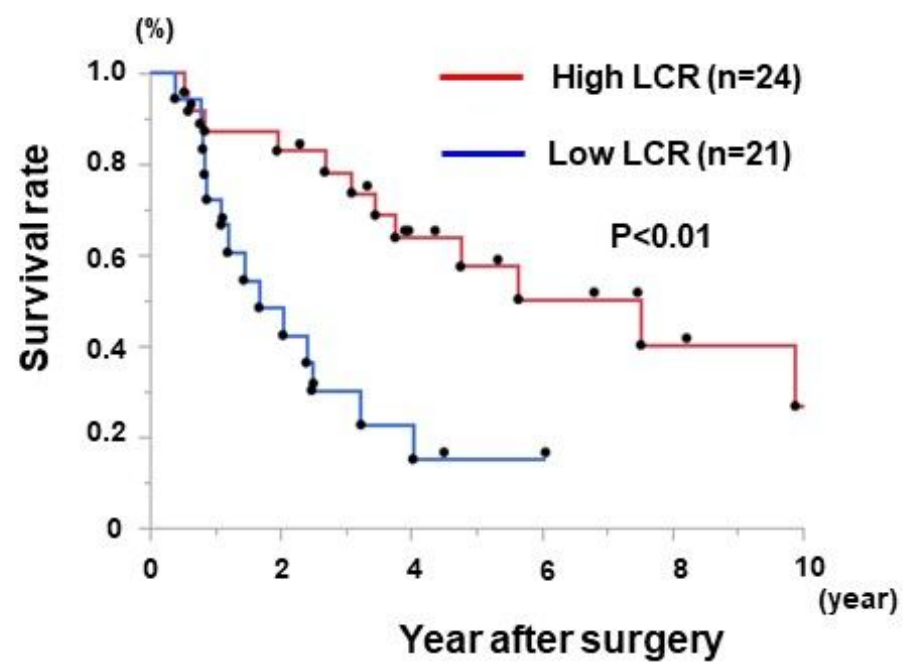

(a)
Disease-free survival

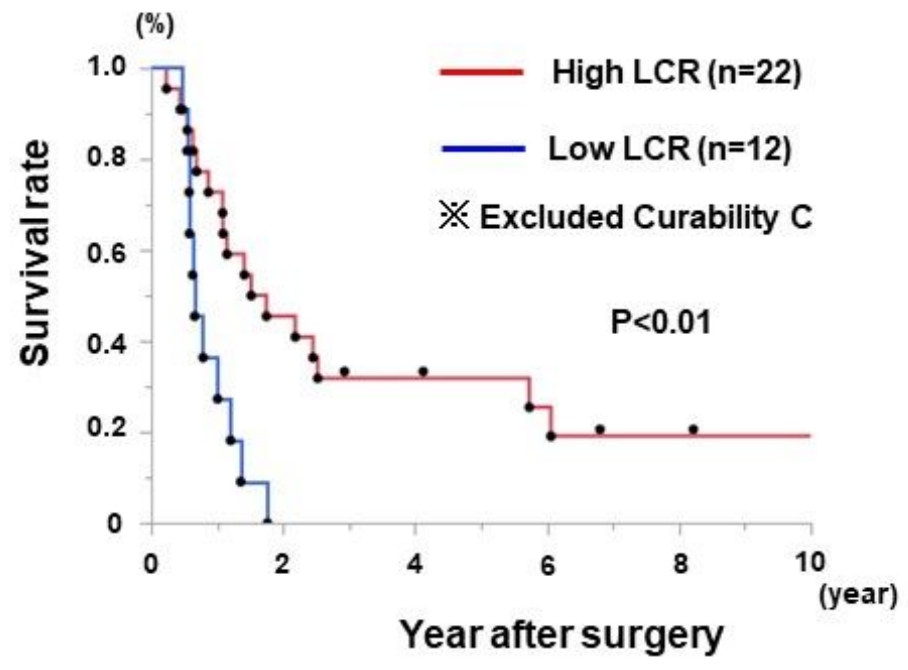

(b)

\section{Figure 3}

\section{Figure 3}

Survival curves. (a) Overall survival rates among patients with high or low lymphocyte/C-reactive protein ratio (LCR; $P<0.01)$. (b) Disease-free survival rate among patients with high or low $L C R(P<0.01)$ 

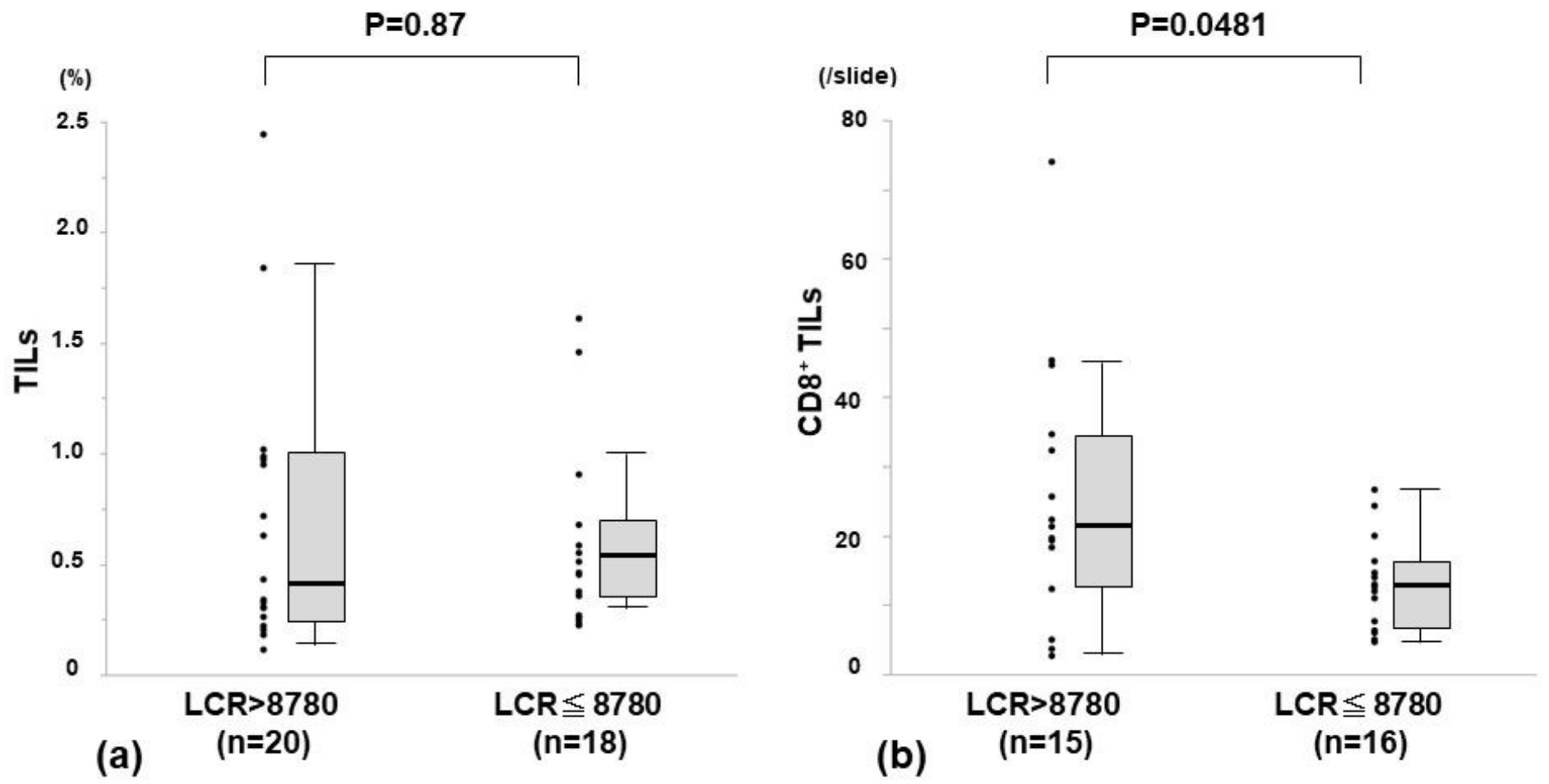

\section{Figure 4}

\section{Figure 4}

Association between LCR and TILs. (a) No significant association was found between lymphocyte/Creactive protein ratio (LCR) and tumor-infiltrating leukocytes (TILs) of all types. (b) Lymphocyte/C-reactive protein ratio $(\mathrm{LCR})$ was significantly related to $\mathrm{CD} 8+\mathrm{TILs}(\mathrm{P}=0.0481)$. 

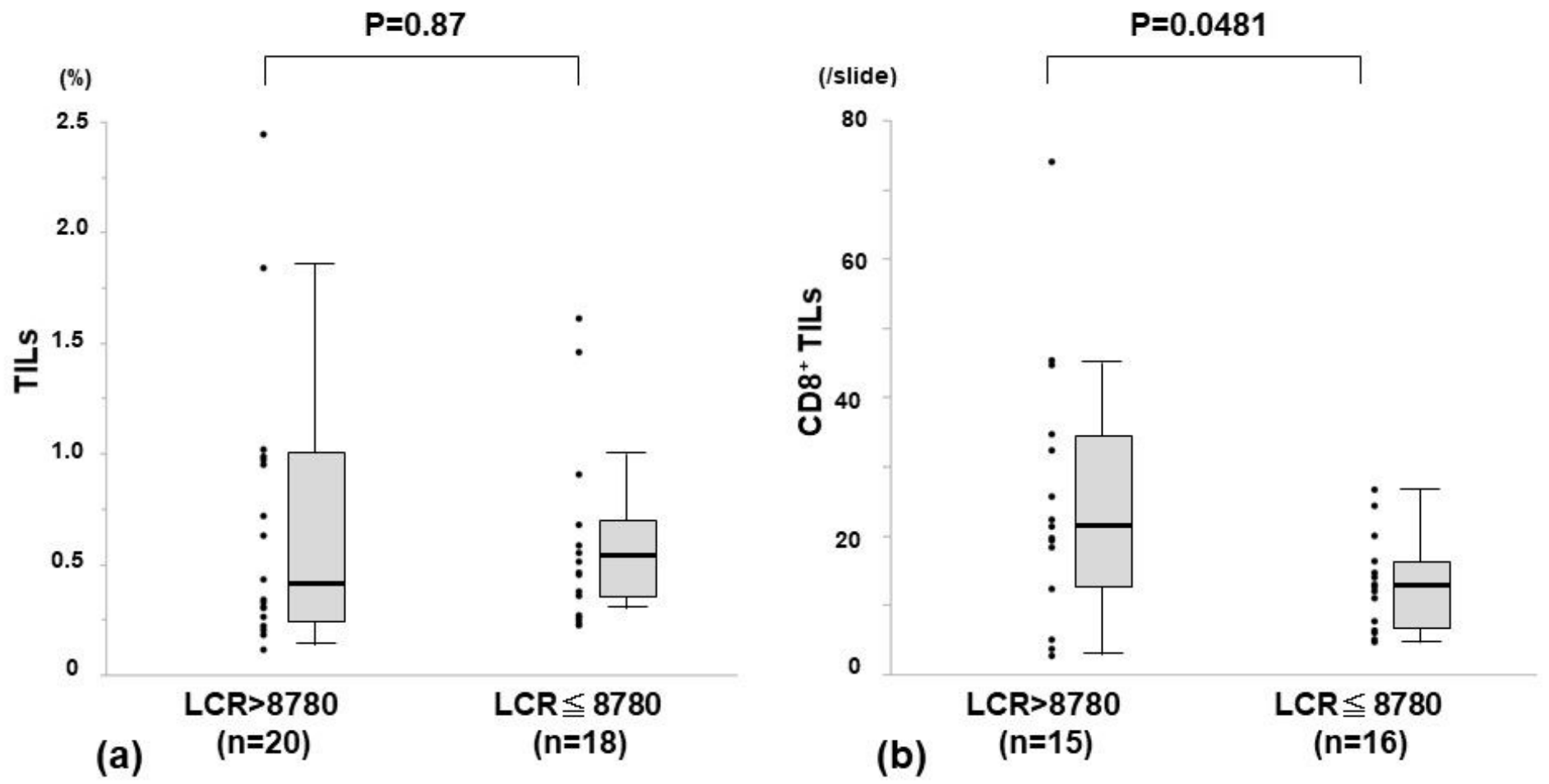

\section{Figure 4}

\section{Figure 4}

Association between LCR and TILs. (a) No significant association was found between lymphocyte/Creactive protein ratio (LCR) and tumor-infiltrating leukocytes (TILs) of all types. (b) Lymphocyte/C-reactive protein ratio $(\mathrm{LCR})$ was significantly related to $\mathrm{CD} 8+\mathrm{TILs}(\mathrm{P}=0.0481)$. 

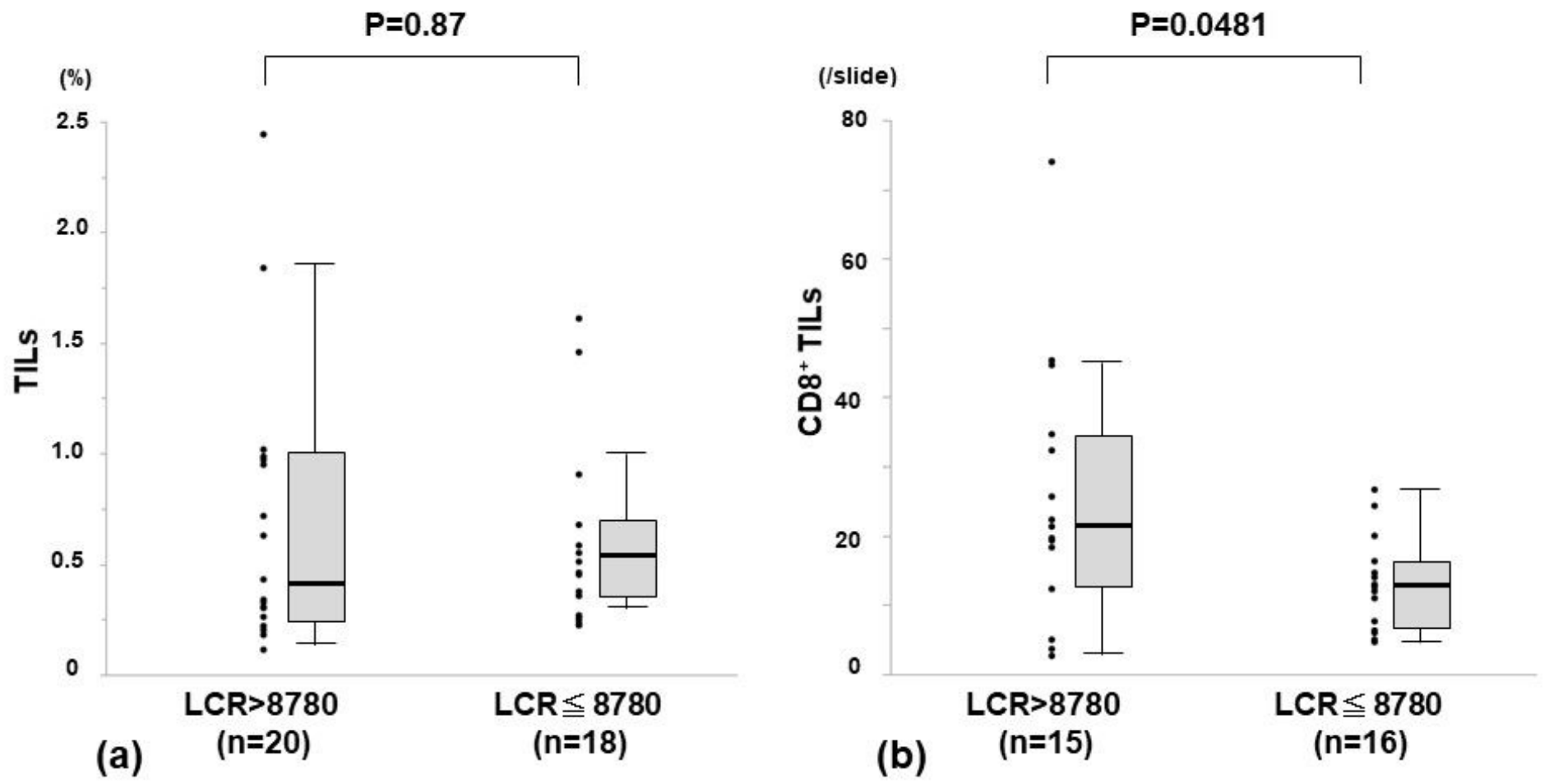

\section{Figure 4}

\section{Figure 4}

Association between LCR and TILs. (a) No significant association was found between lymphocyte/Creactive protein ratio (LCR) and tumor-infiltrating leukocytes (TILs) of all types. (b) Lymphocyte/C-reactive protein ratio $(\mathrm{LCR})$ was significantly related to $\mathrm{CD} 8+\mathrm{TILs}(\mathrm{P}=0.0481)$. 